\title{
Aliskiren, a novel renin inhibitor, is renoprotective in a model of advanced diabetic nephropathy in rats
}

\author{
D. J. Kelly • Y. Zhang • G. Moe • G. Naik • R. E. Gilbert
}

Received: 30 March 2007 / Accepted: 11 July 2007 / Published online: 8 September 2007

(C) Springer-Verlag 2007

\begin{abstract}
Aims/hypothesis Blockade of the renin-angiotensin system (RAS) with either ACE inhibitors or angiotensin receptor blocker is a key therapeutic strategy in slowing progression of diabetic nephropathy. Interruption of the RAS may also be achieved by blocking the activity of renin, the rate-limiting step in angiotensin II biosynthesis. However, it is not known whether drugs in this class also reduce the structural and functional manifestations of diabetic nephropathy.

Methods Using diabetic transgenic (mRen-2)27 rats, a rodent model of advanced diabetic nephropathy, we compared the efficacy of the renin inhibitor, aliskiren (10 $\mathrm{mg} \mathrm{kg}^{-1}$ day $^{-1}$ by osmotic mini-pump), with the ACE inhibitor, perindopril $\left(0.2 \mathrm{mg} \mathrm{kg}^{-1} \mathrm{day}^{-1}\right.$ in drinking water), over a 16 week period.

Results Both perindopril and aliskiren reduced blood pressure, albuminuria and structural injury in experimental diabetic nephropathy, although not to the same extent. Aliskiren, at the dose used, did not reduce systemic blood pressure as much as perindopril, but both compounds were equally effective in reducing albuminuria and glomerulosclerosis in diabetic animals. The magnitude of interstitial fibrosis was attenuated to a greater degree by aliskiren than by perindopril.
\end{abstract}

D. J. Kelly $(\bowtie) \cdot$ Y. Zhang $\cdot$ R. E. Gilbert

Department of Medicine, St Vincent's Hospital,

University of Melbourne,

Fitzroy, VIC 3065, Australia

e-mail: dkelly@medstv.unimelb.edu.au

G. Moe $\cdot$ G. Naik $\cdot$ R. E. Gilbert

Department of Medicine, St Michael's Hospital,

University of Toronto,

Toronto, ON, Canada
Conclusions/interpretation These findings suggest that therapies aimed at different targets within the RAS may not have identical effects in attenuating structural injury in experimental diabetic nephropathy.

Keywords Aliskiren · Diabetic nephropathy · Renin

$\begin{array}{ll}\text { Abbreviations } \\ \text { ARB } & \text { angiotensin receptor blocker } \\ \text { RAS } & \text { renin-angiotensin system } \\ \text { SBP } & \text { systolic blood pressure } \\ \text { STZ } & \text { streptozotocin }\end{array}$

\section{Introduction}

Diabetic nephropathy is a leading cause of end-stage renal disease throughout much of the World [1], accounting for more than one-third of new cases in the USA. Current treatment, aimed at slowing progression of disease, centres on two inter-related therapeutic strategies: blood pressure reduction and blockade of the renin-angiotensin system (RAS) [2-4]. Such treatments have been shown to reduce the functional changes seen in diabetic nephropathy and also to attenuate the structural abnormalities that characterise this disease $[5,6]$.

At present, blockade of the RAS is achieved by two major drug classes: ACE inhibitors and angiotensin receptor blockers (ARB), agents that also lower systemic blood pressure. Attempts to maximise the effectiveness of this strategy have led to the use of ACE inhibitor+ ARB combinations [7], as well as supra-maximal and ultra-high doses of single agents $[8,9]$. More recently, renin inhibition has also emerged as a potential therapeutic strategy to block the RAS and lower blood pressure [10]. However, it is not 
known whether such treatment in diabetic patients leads to organ protection comparable to that achieved by more conventional RAS blockade. Accordingly, in the present study we sought to determine the relative effectiveness of renin vs ACE inhibition on the structural and functional abnormalities of experimental diabetic nephropathy, hypothesising that the two strategies of RAS blockade would be similarly efficacious. The study was undertaken in the transgenic (mRen-2)27 rat, which expresses mouse renin. Heterozygous Ren-2 rats have modest changes in kidney structure and function changes, but develop advanced nephropathic changes after induction of streptozotocin (STZ)-diabetes [11].

\section{Methods}

Animals Six-week-old female, heterozygous (mRen-2)27 rats (St Vincent's Hospital Animal House, Melbourne, VIC, Australia) were assigned to receive either $55 \mathrm{mg} / \mathrm{kg}$ of STZ (Sigma, St Louis, MO, USA) diluted in $0.1 \mathrm{~mol} / 1$ citrate buffer, $\mathrm{pH} 4.5$, or citrate buffer alone (non-diabetic) by tail vein injection following an overnight fast. Diabetic rats were then randomised into three groups $(n=10)$, receiving one of the following treatments: (1) the renin inhibitor, aliskiren (gift of Novartis, NJ, USA), $10 \mathrm{mg} \mathrm{kg}^{-1}$ day $^{-1}$ via osmotic mini-pump; (2) the ACE inhibitor, perindopril (Technologie Servier Laboratories, Paris, France), $0.2 \mathrm{mg}$ $\mathrm{kg}^{-1}$ day $^{-1}$ in drinking water; or (3) no treatment for 16 weeks. Treatment commenced within $24 \mathrm{~h}$ of STZ or citrate buffer injection. All rats had free access to normal rat chow (Ridley Agriproducts, Pakenham, VIC, Australia) and drinking water. They were housed in a stable environment maintained at $22 \pm 1^{\circ} \mathrm{C}(12 \mathrm{~h} \mathrm{light-dark} \mathrm{cycle} \mathrm{with} \mathrm{lights} \mathrm{on}$ at 06:00 hours).

Each week, rats were weighed and their blood glucose levels were measured (Accu-check Advantage II blood glucose monitor; Roche Diagnostic Australia, Castle Hill, NSW, Australia). Only STZ-treated animals with blood glucose $>15 \mathrm{mmol} / 1$ were considered diabetic. Every 4 weeks, SBP was determined in preheated conscious rats via tail-cuff plethysmography [12] using a non-invasive blood pressure controller and Powerlab system (AD Instruments, Bella Vista, NSW, Australia). $\mathrm{HbA}_{1 \mathrm{c}}$ was measured by HPLC at the end of the study. Diabetic rats received a daily injection of insulin (2-4 U i.p.; Humulin NPH, Eli Lilly, Indianapolis, IN, USA) to reduce mortality and promote weight gain. Experimental procedures adhered to the National Health and Medical Research Council of Australia's Code for the Care and Use of Animals for Scientific Purposes and were approved by the Animal Research Ethics Committee of St Vincent's Hospital.
Albuminuria Rats were individually housed in metabolism cages at 16 weeks, habituated for 2 to $3 \mathrm{~h}$ and urine collected over $24 \mathrm{~h}$. During this period animals continued to have free access to tap water and standard laboratory chow. After $24 \mathrm{~h}$ in metabolism cages, a sample of urine $(5 \mathrm{ml})$ was collected from the $24 \mathrm{~h}$ urine sample and stored at $-70^{\circ} \mathrm{C}$ for subsequent analysis of albumin by RIA as previously performed [13].

Tissue preparation Rats were anaesthetised (Nembutal $60 \mathrm{mg} / \mathrm{kg}$ body weight i.p.; Rhone Merieux Australia, Pinkenba, QLD, Australia) and the abdominal aorta cannulated with an $18 \mathrm{G}$ needle. Perfusion-exsanguination commenced at SBP $180-220 \mathrm{mmHg}$ via the abdominal aorta with $0.1 \mathrm{~mol} / \mathrm{l} \mathrm{PBS}, \mathrm{pH} 7.4$ (20 to $50 \mathrm{ml})$, to remove circulating blood. Simultaneously, the inferior vena cava adjacent to the renal vein was severed, allowing free flow of the perfusate. After clearance of circulating blood, 4\% paraformaldehyde (wt/wt) in $0.1 \mathrm{~mol} / \mathrm{l}$ phosphate buffer, $\mathrm{pH} 7.4$, was perfused for a further $5 \mathrm{~min}(100$ to $200 \mathrm{ml}$ of fixative). Kidneys were excised and de-capsulated. The left kidney was snap-frozen in liquid nitrogen and stored at $-80^{\circ} \mathrm{C}$. The right kidney was sliced transversely and paraffinembedded for subsequent light microscopic evaluation.

Histopathology Changes in kidney structure were assessed in a masked protocol in at least 25 randomly selected tissue sections from each group studied. Sections were stained with either haematoxylin and eosin, periodic acid-Schiff's reagent or Masson's modified trichrome to assess glomerulosclerosis and demonstrate collagenous tubulointerstitial matrix, respectively.

Glomerulosclerotic index In $4 \mu \mathrm{m}$ kidney sections stained with periodic acid-Schiff's reagent, 150 glomeruli from each animal were examined in a masked protocol. The extent of sclerosis in each glomerulus was subjectively graded on a scale of 0 to 4, as previously described [13], with the following grades: grade 0 normal, grade 1 sclerotic area $<25 \%$ (minimal), grade 2 sclerotic area $25-50 \%$ (moderate), grade 3 sclerotic area $50-75 \%$ (moderate to severe) and grade 4 sclerotic area $75-100 \%$ (severe). A glomerulosclerotic index was then calculated using the formula:

$\mathrm{GSI}=\sum_{i=0}^{4} \mathrm{Fi}(i)$

where GSI is glomerulosclerotic index and $\mathrm{Fi}$ is the $\%$ of glomeruli in the rat with a given score $(i)$.

Quantitation of matrix deposition The accumulation of matrix within the tubulointerstitium was assessed on Masson's trichrome-stained sections using computer-assisted image 
analysis, as previously reported $[14,15]$. Briefly, ten random non-overlapping fields of each section from ten rats per group were captured and digitised using a BX50 microscope (Olympus Optical, Shibuya-Ku, Tokyo, Japan) attached to a Fujix HC5000 digital camera (Fuji Photo Film, Minato-Ku, Tokyo, Japan). Digital images were then loaded onto a Pentium III IBM computer. An area of blue on a trichromestained section was selected for its colour range and the proportional area of tissue with this range of colour was then quantified. Calculation of the proportional area stained blue (matrix) was then determined using image analysis (Analytical Imaging Station, version 6.0; Imaging Research, St Catherines, ON, Canada).

Kidney aldosterone Kidney aldosterone was assayed by RIA, following tissue extraction, as previously described [16]. In brief, kidney tissue stored at $-80^{\circ} \mathrm{C}$ was boiled in $0.1 \mathrm{~mol} / 1$ acetic acid for $10 \mathrm{~min}$ then homogenised (Polytron; Brinkmann Instruments, Streetsville, ON, Canada). Samples were cooled on ice followed by centrifugation at $2,000 \times \mathrm{g}$ for $20 \mathrm{~min}$ at $4^{\circ} \mathrm{C}$, after which the supernatant fraction was decanted. The pellet was reextracted with cold methanol, homogenised and centrifuged. The methanol supernatant fraction was decanted, dried in a vacuum concentrator (Savant, Farmingdale, NY, USA), then reconstituted with aldosterone RIA zero calibrator buffer (Diagnostic Products Corporation, Los Angeles, CA, USA), vortexed and assayed in parallel with aldosterone standards. Samples or standards were pipetted into aldosterone antibody-coated tubes, followed by the addition of ${ }^{125}$ I-labelled aldosterone tracer, and incubated for $18 \mathrm{~h}$ at room temperature. The liquid aspirate and ${ }^{125} \mathrm{I}$ labelled aldosterone bound to coated tubes were counted in a gamma counter (1470 Wizard; Wallac, Turku, Finland) for $1 \mathrm{~min}$. Bound relative to net total binding percentages $\left(\% B / B_{0}\right)$ for standards were calculated and transformed to $\operatorname{logit}\left(\% B / B_{0}\right)$ vs log aldosterone standard concentrations. A linear regression equation was generated, from which the quantity of aldosterone was determined and expressed as $\mathrm{fmol} / \mathrm{g}$ tissue.
Statistics Data are expressed as means \pm SEM unless otherwise stated. Statistical significance was determined by a two-way ANOVA with a Fisher's post hoc comparison. Albuminuria had a skewed distribution and was analysed following $\log$ transformation and presented as geometric means multiplied or divided by tolerance factors. Analyses were performed using Statview II+ Graphics package (Abacus Concepts, Berkeley, CA, USA) on an Apple Macintosh G4 computer (Apple Computer, Cupertino, CA, USA). A $p$ value of $<0.05$ was regarded as statistically significant.

\section{Results}

Animal characteristics In comparison with control animals, diabetic rats had reduced body weight, which was unaffected by treatment. Kidney weight was elevated with diabetes and not altered by treatment. Plasma glucose and $\mathrm{HbA}_{1 \mathrm{c}}$ were elevated to a similar extent in all diabetic rat groups, irrespective of treatment (Table 1).

Diabetic animals had higher blood pressure than nondiabetic rats. Both perindopril and aliskiren reduced SBP in diabetic rats (Table 1), the reduction being greater in perindopril-treated animals than in those receiving aliskiren. No evidence of impaired wound healing at the site of subcutaneous mini-osmotic pump implantation was noted in aliskiren-treated animals.

Albuminuria Urinary albumin excretion was increased in diabetic rats and was similarly lowered by perindopril and aliskiren. A significant correlation between albuminuria and blood pressure was noted in untreated animals (control and diabetic) and in animals treated with perindopril, but not in those that received aliskiren (Fig. 1).

Renal structure Glomerular injury was a prominent feature of diabetic rats, with evidence of both diffuse and nodular glomerulosclerosis (Figs 2 and 3). These changes were

Table 1 Animal characteristics

\begin{tabular}{lllllll}
\hline Treatment groups & $n$ & $\begin{array}{l}\text { Body weight } \\
(\mathrm{g})\end{array}$ & $\begin{array}{l}\text { Kidney weight } \\
(\mathrm{g})\end{array}$ & $\begin{array}{l}\text { Blood glucose } \\
(\mathrm{mmol} / \mathrm{l})\end{array}$ & $\begin{array}{l}\mathrm{HbA}_{1 \mathrm{c}} \\
(\%)\end{array}$ & $\begin{array}{l}\text { AER } \\
(\mathrm{mg} / 24 \mathrm{~h})\end{array}$ \\
\hline Control+vehicle & 10 & $323 \pm 13$ & $1.27 \pm 0.05$ & $6.28 \pm 0.15$ & $3.77 \pm 0.03$ & $0.98 \times / \div 1.32$ \\
$(\mathrm{mmHg})$
\end{tabular}

Values are expressed as the means \pm SEM, except for AER, which is expressed as the mean multiplied or divided by $(\times / \div)$ the tolerance factor ${ }^{\mathrm{a}} p<0.05$ vs control; ${ }^{\mathrm{b}} p<0.01$ vs control; ${ }^{\mathrm{c}} p<0.01$ vs diabetes + vehicle; ${ }^{\mathrm{d}} p<0.05$ vs diabetic treated with aliskiren; ${ }^{\mathrm{e}} p<0.05$ vs diabetes + vehicle 
Fig. 1 Correlation between SBP and AER in rats as follows: a control $(r=0.76$, $p=0.01)$, b diabetic $(r=0.79$, $p=0.01)$, c diabetic treated with perindopril $(r=0.64, p=0.03)$ and $\mathbf{d}$ diabetic treated with aliskiren (not significant). $r$, Pearson correlation coefficient
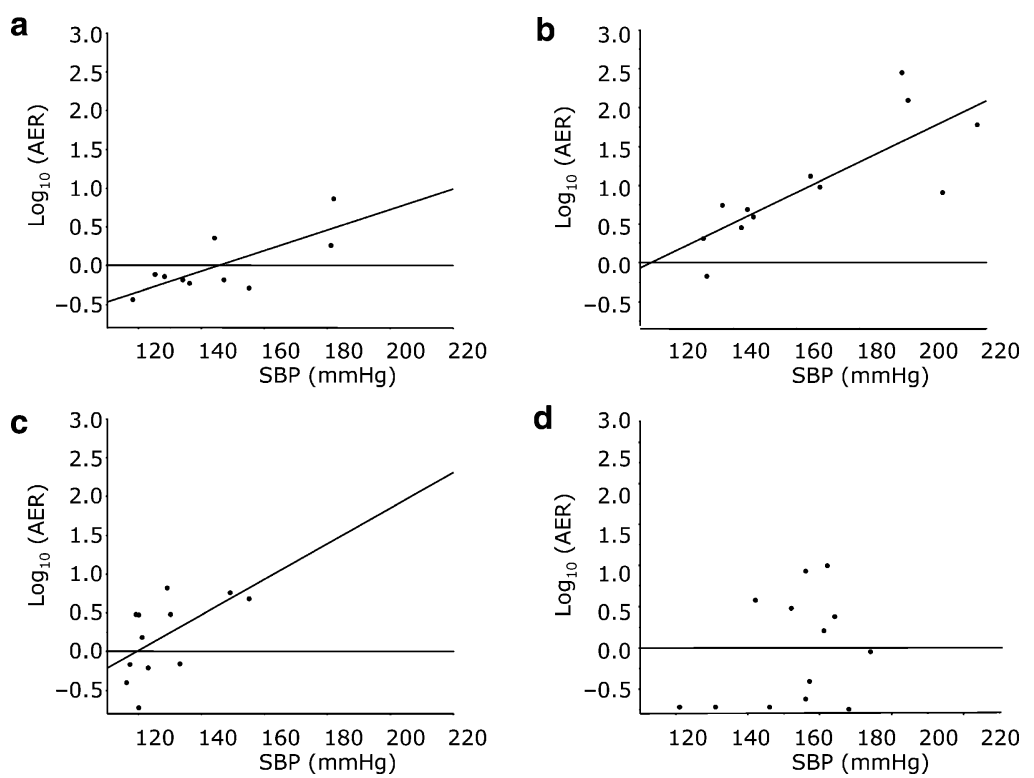

attenuated to a similar extent by treatment with perindopril or aliskiren (Figs 2 and 3).

Substantial interstitial fibrosis was also noted in diabetic rats. This was markedly reduced by treatment with each of the two drugs (Figs 4 and 5). This reduction was greater with aliskiren than with perindopril.

Tissue aldosterone A trend towards reduced kidney aldosterone was noted in diabetic animals compared with control $(794 \pm 127$ vs $521 \pm 128 \mathrm{fmol} / \mathrm{g}$, respectively; $p=0.06)$, that was unaffected by treatment with either perindopril $(592 \pm 128 \mathrm{fmol} / \mathrm{g})$ or aliskiren $(565 \pm 343 \mathrm{fmol} / \mathrm{g})$.

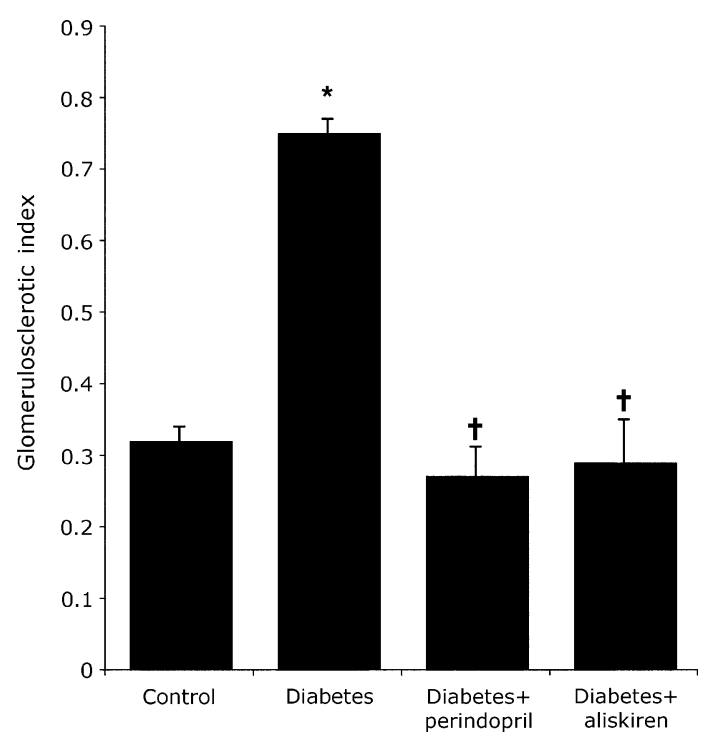

Fig. 2 Glomerulosclerotic index in control and diabetic Ren-2 rats, treated or not with aliskiren and perindopril. ${ }^{*} p<0.05$ vs control; $\dagger p<$ 0.05 vs diabetic

\section{Discussion}

The ACE inhibitor perindopril and the renin inhibitor aliskiren both reduced blood pressure, albuminuria and structural injury in experimental diabetic nephropathy, although not to the same extent. Indeed, despite a lesser reduction of blood pressure compared with perindopril, aliskiren was equally beneficial in reducing albuminuria

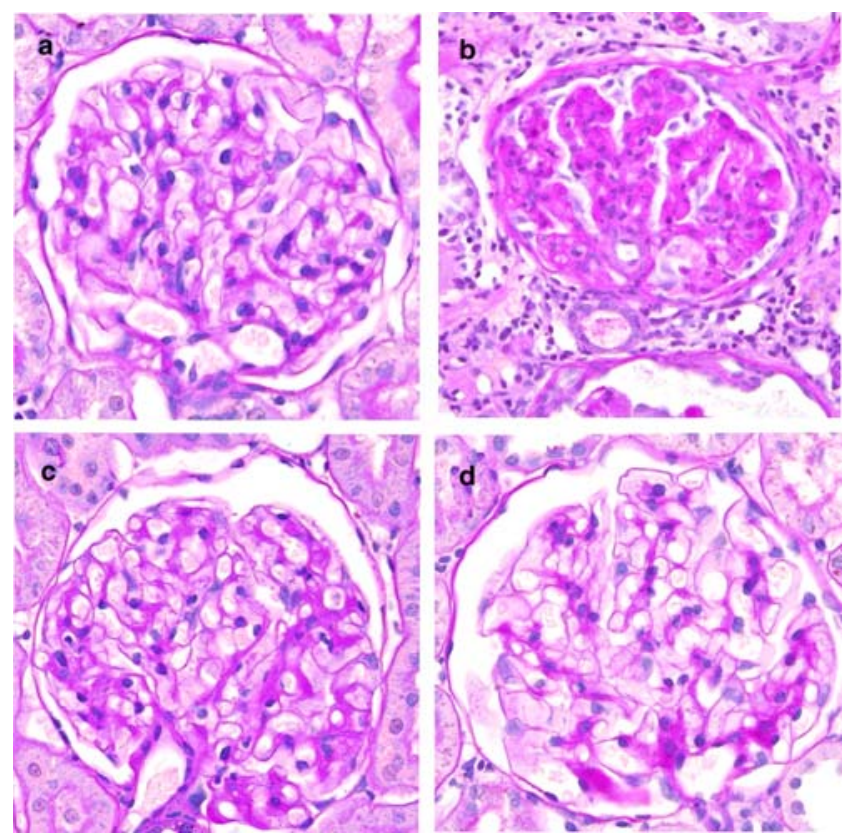

Fig. 3 Representative periodic acid-Schiff's reagent-stained sections from control and diabetic Ren-2 rats treated or not with aliskiren and perindopril. In control (a) rats only minimal glomerulosclerosis was noted, while diabetes (b) was associated with marked glomerulosclerosis. Treatment of diabetic rats with perindopril (c) or aliskiren (d) was associated with a reduction in the glomerulosclerosis 


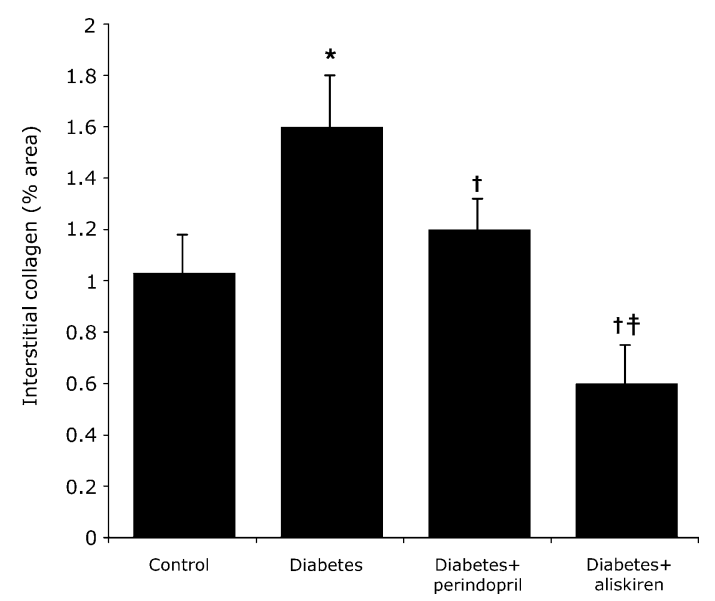

Fig. 4 Interstitial fibrosis in control and diabetic Ren-2 rats, treated or not with aliskiren and perindopril. Interstitial fibrosis is expressed as the proportional area occupied by collagenous matrix on Masson's trichrome-stained sections. ${ }^{*} p<0.05$ vs control; $\dagger p<0.05$ vs diabetic; $\$ p<0.05$ vs diabetic treated with perindopril

and the degree of glomerulosclerosis in diabetic animals. Interstitial fibrosis was attenuated to a greater extent by aliskiren than by perindopril.

In this study only a single dose of each drug was chosen, aiming to achieve similar blood pressure reductions in both treatment groups. Although dose selection was based on previous reports [17, 18], the current study found that, notwithstanding the limitations of tail-cuff sphygmomanometry, the ACE inhibitor perindopril lowered systemic blood pressure to a greater extent than aliskiren, with a mean difference of $36 \mathrm{mmHg}$ between the two treatment groups.
Had we used higher doses of aliskiren or lower doses of perindopril, we might have obtained equivalent blood pressure values in both treated groups. However, despite the substantially higher blood pressure in the aliskiren-treated group, glomerulosclerosis and albuminuria were improved to a similar extent to the respective improvements in perindopriltreated animals.

In patients with kidney disease blood pressure correlates closely with the magnitude of proteinuria [19] while reduction of blood pressure using conventional, non-RAS related anti-hypertensive agents lowers proteinuria [20]. In patients with diabetic nephropathy, ACE inhibitor and ARB therapy reduce proteinuria not only by lowering systemic blood pressure but also by a range of intra-renal effects including modulation of intra-glomerular pressure, permeability and matrix protein production [21]. In the present study, we found a close correlation between albuminuria and blood pressure in untreated control and diabetic rats. The relationship, although somewhat diminished, was still present in perindopril-treated diabetic rats, suggesting that some of the variance in albuminuria found in this group, was due to differences in blood pressure. By contrast, no correlation between albuminuria and blood pressure was seen in aliskiren-treated animals. These findings indicate that the variance in albuminuria in this group is unlikely to be due to the effects of aliskiren on systemic blood pressure, suggesting that intra-renal effects may be more prominent with this drug.

The kidney has a finite capacity to regulate intraglomerular pressure such that some transmission of systemic
Fig. 5 Representative Masson's trichrome-stained sections from control and diabetic Ren-2 rats treated or not with aliskiren or perindopril. In control (a) rats, very little collagen (blue staining) is present within the interstitium, while extensive interstitial fibrosis was noted in diabetic animals (b). Interstitial fibrosis in diabetic rats was reduced by perindopril (c) and to a greater extent by aliskiren (d). Original magnification $\times 350$
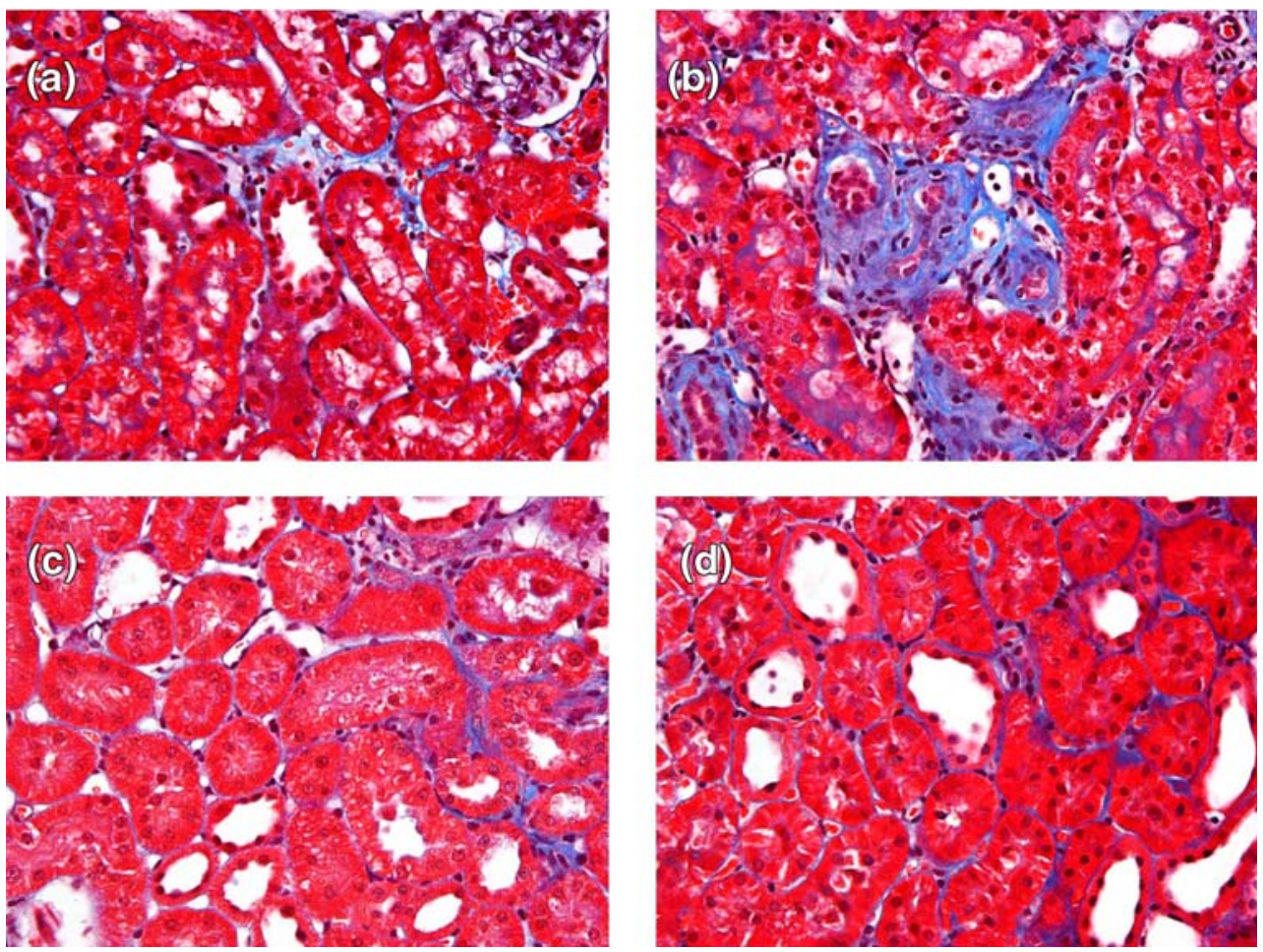
pressures to the glomerular tuft still occurs [22]. These effects are magnified by the local synthesis of angiotensin II, which by preferentially constricting the efferent arteriole raises intra-glomerular pressure further and induces the expression of fibrotic growth factors that lead to glomerulosclerosis $[21,23]$. Consistent with this, blockade of the RAS by ACE inhibition reduces both systemic blood pressure and local angiotensin II formation, leading to reductions in glomerulosclerosis and renal dysfunction that cannot be explained by blood pressure reduction alone [24, 25]. However, the relative importance of systemic blood pressure vs local angiotensin II production in providing this 'renoprotection' has not been precisely defined. In the present study, both perindopril and aliskiren reduced glomerulosclerosis to similar degrees, despite differing effects on systemic blood pressure.

Tubulointerstitial injury is a major feature of diabetic nephropathy [26] and also an important predictor of renal dysfunction [27, 28] and the response to therapeutic interventions in both the experimental and human settings $[6,29,30]$. In the present study, aliskiren attenuated tubulointerstitial fibrosis to a greater extent than perindopril. While the mechanisms underlying the different effects of these two agents was not explored in this study, it is conceivable that the recently described pro-renin/renin receptor [31], which is predominantly expressed in the renal tubular epithelium [32], could have contributed.

The insertion of the mouse Ren-2 transgene into the genome of the Sprague-Dawley rat leads in hypertension to a range of alterations to plasma and tissue components of the RAS [33-35]. Compared with Sprague-Dawley animals, non-diabetic Ren-2 rats are characterised by increased plasma total renin, pro-renin and angiotensin II, along with increased kidney angiotensin II despite lower levels of kidney renin $[35,36]$. The induction of STZ diabetes leads to further changes in the RAS, with a relative reduction in kidney angiotensin II in comparison with non-diabetic Ren2 rats [36]. In the present study, we found a trend for kidney aldosterone to be similarly reduced in diabetic Ren-2 rats, but that this was unaffected by perindopril or aliskiren, consistent with reports that both angiotensin-dependent and independent mechanisms contribute to renal aldosterone synthesis in the rat kidney [37].

In summary, the present study suggests that renin inhibition with aliskiren is renoprotective in experimental advanced diabetic nephropathy, with effects that are similar but not identical to those caused by ACE inhibition. At present it is uncertain whether additional effects might be achievable at higher dose or whether the demonstrated changes are applicable to other disease models and to humans. It is also uncertain whether additional renoprotection can be achieved by combining renin inhibition with more conventional blockers of the RAS.
Acknowledgements This project was supported by a programme grant from the Juvenile Diabetes Research Foundation, the National Health and Medical Research Council of Australia and a research grant from Novartis Institutes for Biomedical Research. D. J. Kelly is a recipient of a Career Development Award from the Juvenile Diabetes Research Foundation. The authors would like to thank M. Pacheco, J. Court and L. Di Rago for the expert technical assistance.

Duality of interest R. E. Gilbert and D. J. Kelly have received grants from Novartis Pharmaceuticals, the makers of aliskiren.

\section{References}

1. Ritz E, Rychlik I, Locatelli F, Halimi S (1999) End-stage renal failure in type 2 diabetes: a medical catastrophe of worldwide dimensions. Am J Kidney Dis 34:795-808

2. Bakris GL, Williams M, Dworkin L et al (2000) Preserving renal function in adults with hypertension and diabetes: a consensus approach. National Kidney Foundation Hypertension and Diabetes Executive Committees Working Group. Am J Kidney Dis 36:646-661

3. Lewis EJ, Hunsicker LG, Clarke WR et al (2001) Renoprotective effect of the angiotensin-receptor antagonist irbesartan in patients with nephropathy due to type 2 diabetes. N Engl J Med 345:851-860

4. Brenner BM, Cooper ME, de Zeeuw D et al (2001) Effects of losartan on renal and cardiovascular outcomes in patients with type 2 diabetes and nephropathy. N Engl J Med 345:861-869

5. Nankervis A, Nicholls K, Kilmartin G, Allen P, Ratnaike S, Martin FI (1998) Effects of perindopril on renal histomorphometry in diabetic subjects with microalbuminuria: a 3-year placebocontrolled biopsy study. Metabolism 47:12-15

6. Cordonnier DJ, Pinel N, Barro C et al (1999) Expansion of cortical interstitium is limited by converting enzyme inhibition in type 2 diabetic patients with glomerulosclerosis. J Am Soc Nephrol 10:1253-1263

7. Rossing K, Jacobsen P, Pietraszek L, Parving HH (2003) Renoprotective effects of adding angiotensin II receptor blocker to maximal recommended doses of ACE inhibitor in diabetic nephropathy: a randomized double-blind crossover trial. Diabetes Care 26:2268-2274

8. Weinberg AJ, Zappe DH, Ashton M, Weinberg MS (2004) Safety and tolerability of high-dose angiotensin receptor blocker therapy in patients with chronic kidney disease: a pilot study. Am J Nephrol 24:340-345

9. Rossing K, Schjoedt KJ, Jensen BR, Boomsma F, Parving HH (2005) Enhanced renoprotective effects of ultrahigh doses of irbesartan in patients with type 2 diabetes and microalbuminuria. Kidney Int 68:1190-1198

10. Staessen JA, Li Y, Richart T (2006) Oral renin inhibitors. Lancet 368:1449-1456

11. Kelly DJ, Wilkinson-Berka JL, Allen TJ, Cooper ME, Skinner SL (1998) A new model of diabetic nephropathy with progressive renal impairment in the transgenic (mRen-2)27 rat. Kidney Int $54: 343-352$

12. Bunag RD (1973) Validation in awake rats of a tail-cuff method for measuring systolic pressure. J Appl Physiol 34:279-282

13. Kelly DJ, Hepper C, Zhang Y, Jaworski K, Wilkinson-Berka JL, Gilbert RE (2003) Protein kinase C $\beta$ inhibition attenuates the progression of experimental diabetic nephropathy in the presence of continued hypertension. Diabetes 52:512-518

14. Lehr HA, Mankoff DA, Corwin D, Santeusanio G, Gown AM (1997) Application of Photoshop-based image analysis to quantification of hormone receptor expression in breast cancer. J Histochem Cytochem 45:1559-1565 
15. Lehr HA, van der Loos CM, Teeling P, Gown AM (1999) Complete chromogen separation and analysis in double immunohistochemical stains using Photoshop-based image analysis. J Histochem Cytochem 47:119-126

16. Naik GO, Moe GW, Armstrong PW (2001) Specific and nonspecific measurements of tissue angiotensin II cascade members. J Pharm Biomed Anal 24:947-955

17. Pilz B, Shagdarsuren E, Wellner M et al (2005) Aliskiren, a human renin inhibitor, ameliorates cardiac and renal damage in double-transgenic rats. Hypertension 46:569-576

18. Mifsud SA, Skinner SL, Cooper ME, Kelly DJ, Wilkinson-Berka JL (2002) Effects of low-dose and early versus late perindopril treatment on the progression of severe diabetic nephropathy in (mREN-2)27 rats. J Am Soc Nephrol 13:684-692

19. Peterson JC, Adler S, Burkart JM et al (1995) Blood pressure control, proteinuria, and the progression of renal disease. The Modification of Diet in Renal Disease Study. Ann Intern Med 123:754-762

20. Parving HH, Andersen AR, Smidt UM, Svendsen PA (1983) Early aggressive antihypertensive treatment reduces rate of decline in kidney function in diabetic nephropathy. Lancet 1:1175-1179

21. Johnston CI, Risvanis J, Naitoh M, Tikkanen I (1998) Mechanism of progression of renal disease-current hemodynamic concepts. J Hypertens 16:S3-S7

22. Brenner BM (1983) Hemodynamically mediated glomerular injury and the progressive nature of kidney disease. Kidney Int 23:647-655

23. Anderson S (1997) Role of local and systemic angiotensin in diabetic renal disease. Kidney Int 52(63):S107-S110

24. Zatz R, Dunn BR, Meyer TW, Anderson S, Rennke HG, Brenner BM (1986) Prevention of diabetic glomerulopathy by pharmacological amelioration of glomerular capillary hypertension. J Clin Invest 77:1925-1930

25. Anderson S, Rennke HG, Brenner BM (1986) Therapeutic advantage of converting enzyme inhibitors in arresting progressive renal disease associated with systemic hypertension in the rat. J Clin Invest 77:1993-2000

26. Gilbert RE, Cooper ME (1999) The tubulointerstitium in progressive diabetic kidney disease: more than an aftermath of glomerular injury? Kidney Int 56:1627-1637
27. Bader R, Bader E, Grung KE, Markensen-Haen S, Christ H, Bohle A (1980) Structure and function of the kidney in diabetic glomerulosclerosis: correlations between morphological and functional parameters. Pathol Res Pract 167:204-216

28. Lane P, Steffes MW, Fioretto P, Mauer SM (1993) Renal interstitial expansion in insulin-dependent diabetes mellitus. Kidney Int 43:661-667

29. Gilbert RE, Cox A, Wu LL et al (1998) Expression of transforming growth factor- $\beta 1$ and type IV collagen in the renal tubulointerstitium in experimental diabetes: effects of angiotensin converting enzyme inhibition. Diabetes 47:414-422

30. Kelly DJ, Gilbert RE, Cox AJ, Soulis T, Jerums GT, Cooper ME (2001) Aminoguanidine ameliorates overexpression of prosclerotic growth factors and collagen deposition in experimental diabetic nephropathy. J Am Soc Nephrol 12:2098-2107

31. Nguyen G, Delarue F, Burckle C, Bouzhir L, Giller T, Sraer JD (2002) Pivotal role of the renin/prorenin receptor in angiotensin II production and cellular responses to renin. J Clin Invest 109: $1417-1427$

32. Nguyen G (2006) Increased cyclooxygenase-2, hyperfiltration, glomerulosclerosis, and diabetic nephropathy: put the blame on the (pro)renin receptor? Kidney Int 70:618-620

33. Mullins JJ, Peters J, Ganten D (1990) Fulminant hypertension in transgenic rats harbouring the mouse Ren-2 gene. Nature 344: $541-544$

34. Peters J, Munter K, Bader M, Hackenthal E, Mullins JJ, Ganten D (1993) Increased adrenal renin in transgenic hypertensive rats, TGR(mREN2)27, and its regulation by cAMP, angiotensin II, and calcium. J Clin Invest 91:742-747

35. Campbell DJ, Rong P, Kladis A, Rees B, Ganten D, Skinner SL (1995) Angiotensin and bradykinin peptides in the TGR(mRen-2) 27 rat. Hypertension 25:1014-1020

36. Campbell DJ, Kelly DJ, Wilkinson-Berka JL, Cooper ME, Skinner SL (1999) Increased bradykinin and "normal" angiotensin peptide levels in diabetic Sprague-Dawley and transgenic (mRen2) 27 rats. Kidney Int 56:211-221

37. Xue C, Siragy HM (2005) Local renal aldosterone system and its regulation by salt, diabetes, and angiotensin II type 1 receptor. Hypertension 46:584-590 